\title{
Comparison of Biological Activities of Synurus deltoides (Aiton) Nakai Under Different Shading Conditions
}

\author{
Yunyao Jiang, Heesum Noh ${ }^{1}$ and Myeong-Hyeon Wang* \\ Department of Medical Biotechnology, Kangwon National University, Chuncheon 200-701, Korea \\ ${ }^{1}$ Specialty Crops Research Institute, Gangwondo Agricultural Research and Extension Services, Pyeongchang \\ 232-923, Korea
}

\begin{abstract}
Shade treatment of Synurus deltoides (Aiton) Nakai was carried out with 0, 35, and 55\% shading net, and samples were marked as no shade, $35 \%$ shade, and $55 \%$ shade, respectively. We examined in vitro antioxidant and anti-inflammatory capacities using a 1,1-diphenyl-2-2-pricylhydrazyl (DPPH) radical scavenging assay, a reducing power assay, a total antioxidant assay, a metal chelating assay, a superoxide radical scavenging assay, and a nitric oxide inhibition assay. As a result, no shade and 35\% shade possessed higher DPPH radical scavenging activity and reducing power ability than that of $55 \%$ shade. Notably, no shade had significantly higher total phenolic and flavonoid contents than those in the other samples. No shade exhibited significantly higher total antioxidant activity than that of $35 \%$ shade and $55 \%$ shade. However, the chelating ability of $55 \%$ shade was significantly greater than that of no shade and $35 \%$ shade; $55 \%$ shade also showed significantly higher anti-inflammatory capacity than that of no shade or $35 \%$ shade.
\end{abstract}

Key words - Anti-inflammatory, Antioxidant, Cytotoxicity, Shade treatment, Phenolic content

\section{Introduction}

Synurus deltoids is a perennial edible herbaceous plant that belongs to the Compositae family and is largely distributed in East Asia. S. deltoids has been used as a folk medicine to treat inflammatory edema, bleeding, vomiting, and urinary inflammation for a long time (Park et al., 2004). Some chemical and pharmacological researches about $S$. deltoides and related species have been reported. Anthocyanins and 20-hydroxyecdysone have been found in this plant, and the antioxidant activity of a hot water extracts of $S$. deltoids has been reported by Jung et al. (2008a). However, the effects of light treatment on the biological activity of $S$. deltoids have not been described. The intensity of photosynthetically active radiation irradiance of UV-exposed plants controls the activities of enzymes and the concentration of metabolites that prevent photo-oxidative damage (Guidi et al., 2011). Different light conditions may have a relatively minor influence on the biochemistry and biological activities of $S$. deltoids growing under natural conditions. The light condition in which plants grow is a very

*Corresponding author. E-mail : mhwang@kangwon.ac.kr important factor for controlling their growth. Therefore, correlative measurements were carried out to compare the extraction yield and biological activities of $S$. deltoids under different light conditions. Additional studies to determine the proper environment are necessary.

Reactive oxygen species (ROS) such as hydrogen peroxide $\left(\mathrm{H}_{2} \mathrm{O}_{2}\right)$, superoxide anions $\left(\mathrm{O}_{2}{ }^{-}\right)$has been considered to be a cause of oxidative damage to biological molecules in the human body (Song et al., 2006). For example, $\mathrm{H}_{2} \mathrm{O}_{2}$ lead to the cell death in many different cell types, but addition of natural antioxidants can provide protection (Jeong et al., 2011). Antioxidant provides protective against free radicals and ROS, and antioxidants are used to keep food quality increase the shelf life by regarding oxidative deterioration of lipids (Tyug et al., 2010). The major antioxidant compounds in plant are polyphenols. Phenolic compounds exhibit protection capacity against oxidative stress and several health beneficial effects such as antioxidant, anti-inflammatory, antihepatotoxic and antitumor activities (Luthria, 2008). Flavonoids as hydrophilic scavengers are a group of polyphenolic compounds. Flavonoids build up these activities as antioxidants and free radical scavengers and exhibit effect on antibacterial, antiviral, anti- 
inflammatory, antiallergic, and vasodilatory actions (Cook and Samman, 1996). Exogenous antioxidants are required to assist the body to decrease the antioxidant stress caused by excess free radicals (Sathuvan et al., 2012). However, there is deep concern about the safety of some common antioxidants such as butylated hydroxyanisole (BHA) and butlylated hydroxytoluene (BHT) as they are toxic, carcinogenic and damage DNA and the liver (Aremu et al., 2011). For this reason, more attention has been focused on research for natural non-toxic antioxidants from plant sources (Milos et al., 2012). Because of the health-promoting potential of natural antioxidants, they should be incorporated into food products as more natural and healthy alternatives instead of some existing synthetic additives such as tocopherol, tertiary-butylhydroquinone, BHA, and BHT (Lue et al., 2010). Therefore, shade treatment of $S$. deltoids was carried out with 0,35 , and $55 \%$ shading net and in vitro antioxidant and anti-inflammatory capacities were examined to determine the effects of different shading conditions on the extraction yield and biological activities.

\section{Materials and Methods}

\section{Plant materials and shading treatments}

S. deltoids was sown in 105 cell tray pots in March 2012 and grown in a grass house. They were planted in a $30 \times 20 \mathrm{~cm}$ field located at the Gangwon Agricultural Research and Extension Services, Specialty Crops Research Institute, Wild Vegetable Branch in Pyeongchang, Gangwon, Korea. The shading treatments were carried out in the last 10 days of May using $35 \%$ and $55 \%$ shading net sold commercially. Light density was measured 10 times at about 11 o'clock using a portable light density measuring instrument (Almemo 2590, FL A603-PS5, Ahlborn, Holzkirchen, Germany) on sunny days from July 26 to September 10 . The average shading effect under the $35 \%$ shading net was $39 \%$ and the average shading effect under the $55 \%$ shading net was $72 \%$. The yields and hardness of the leaves were measured on 15 plants during the first 10 days of August ( 3 months after planting). The hardness of the leaves was measured using a hardness measuring instrument (Rheo-meter Compac-100 II/SUN). The temperatures under the shading treatments were measured with an automatic temperature measuring instrument (Onset, Hobo, Contoocook,
NH, USA) at 1 meter from the ground from May to September. The data were analyzed by SPSS program version 19.0 (SPSS, Inc., Chicago, IL, USA) and were evaluated with Duncan's multiple range test. A $p<0.05$ was considered significant.

\section{Chemicals}

1,1-diphenyl-2-2-pricylhydrazyl (DPPH), 2-deoxy-D-ribose, a-tocopherol, ethylenediaminetetraacetic acid (EDTA), 3-(2pyridyl)-5,6-bis (4-phenyl-sulfonic acid)-1,2,4-triazine (ferrozine), trichloroacetic acid (TCA), Folin-Ciocalteu reagent, BHT, nitro blue tetrazolium (NBT), ferric chloride, phenazine methosulfate (PMS), dinucleotide-reduced (NADH), 1-(4,5dimethylthiazol-2-yl)-3,5-diphenylformazan (MTT), and lipopolysaccharide (LPS) (E. coli 0111:B4) were purchased from Sigma (St, Louis, MO, USA). RPMI medium 1640 and fetal bovine serum (FBS) were acquired from Gibco BRL (Grand Island, NY, USA). All culture supplies were obtained from BD-Falcon (BD, Franklin Lakes, NJ).

\section{Preparation of the extract}

S. deltoides was dried in the shade at room temperature and powdered. One hundred $g$ of the powder was immersed in $2 \mathrm{~L}$ of methanol and extracted with an ultrasonic cleaner for $6 \mathrm{~h}$ at the boiling point. The extract was filtered through filter paper (100 mm; Whatman, Maidstone, UK) and evaporated using a vacuum rotary evaporator (CCA-1110; Eyela, Tokyo, Japan) to produce a crude extract. The dried extract was weighed and kept in a refrigerator for further analysis. The extracts of samples without treatment and treated with $35 \%$ and $55 \%$ shading net were marked as control, $35 \%$ treatment, and 55\% treatment, respectively.

\section{Determination of total phenolic and flavonoid contents}

Total phenolic content was determined using Folin-Ciocalteu reagent according to the method of Jung et al. (2008b) with a slight modification. Samples of $1 \mathrm{mg} / \mathrm{mL}$ and tannic acid of five different concentrations $(20,40,80,160$, and $320 \mu \mathrm{g} / \mathrm{mL})$ were prepared. One hundred $\mu \mathrm{L}$ of sample or tannic acid was mixed with $500 \mu \mathrm{L}$ of $10 \%$ Folin-Ciocalteu reagent. Then, $400 \mu \mathrm{L}$ of sodium carbonate solution $(7.5 \%)$ was added to the mixture. The reactants were mixed adequately. After $30 \mathrm{~min}$ 
at room temperature, the absorbance was measured at $750 \mathrm{~nm}$. Total phenolic content was expressed as mg tannic acid equivalents/g (Tan $\mathrm{mg} / \mathrm{g}$ extract).

Total flavonoid content was determined in $500 \mu \mathrm{L}$ of a $1 \mathrm{mg} / \mathrm{mL}$ sample mixed with $500 \mu \mathrm{L}$ of $2 \% \mathrm{AlCl}_{3}$ solution. The mixed solution was kept at room temperature for $1 \mathrm{~h}$, and absorbance was recorded at $405 \mathrm{~nm}$. Total flavonoid content was expressed as mg quercetin equivalents/g (Que mg/g extract).

\section{DPPH radical-scavenging activity}

The activity of the DPPH scavenging free radical was assessed using the method of Hu et al. (2009a) with a slight modification. Five-hundred $\mu \mathrm{L}$ of a positive control or sample at concentrations of $1-16 \mu \mathrm{g} / \mathrm{mL}$ was mixed with $500 \mu \mathrm{L}$ of $0.1 \mathrm{mM}$ DPPH methanol solution. The mixture was kept in the dark for $30 \mathrm{~min}$ at room temperature after shaking vigorously. Absorbance was measured at $515 \mathrm{~nm}$, and DPPH radical scavenging activity was calculated. BHA and a-tocopherol were used as positive controls.

\section{Reducing power assay}

The reducing power activity of the extract was measured according to the method of $\mathrm{Hu}$ et al. (2009b) with some modifications. Samples was prepared at three concentrations $(100,300$, and $500 \mu \mathrm{g} / \mathrm{mL})$ and $200 \mu \mathrm{L}$ of $0.2 \mathrm{M}$ sodium phosphate buffer ( $\mathrm{pH}$ 6.6) was added to each sample. Then, $200 \mu \mathrm{L}$ of $0.1 \%$ potassium ferricyanide was mixed and the mixture was incubated at $50^{\circ} \mathrm{C}$ for $30 \mathrm{~min}$. After adding $200 \mu \mathrm{L}$ of TCA solution (10\%), the reactants were centrifuged at $574 \times \mathrm{g}$ for $10 \mathrm{~min}$ at room temperature. Then, $500 \mu \mathrm{L}$ of the supernatant was vacuumed out and added to a new tube with $500 \mu \mathrm{L}$ of distilled water and $100 \mu \mathrm{L}$ of $0.1 \%$ ferric chloride. The absorbance was determined at $700 \mathrm{~nm}$. Ascorbic acid was used as the positive control.

\section{Metal chelating activity}

Metal chelating activity of the extracts was measured according to Liu et al. (2011) with a slight modification. Samples $(200 \mu \mathrm{L})$ at four different concentrations $(0.5,1,2$, and $4 \mathrm{mg} / \mathrm{mL}$ ) were mixed with $20 \mu \mathrm{L}$ of $2 \mathrm{mM} \mathrm{FeCl}_{2}$ in $740 \mu \mathrm{L}$ of methanol. Then, $40 \mu \mathrm{L}$ of $5 \mathrm{mM}$ ferrozine was added to initiate the reaction. The mixture was kept at room temperature for $10 \mathrm{~min}$, and absorbance of the solution was determined at $562 \mathrm{~nm}$. BHA and EDTA were used as positive controls.

\section{Superoxide radical scavenging assay}

Superoxide radical scavenging activity was determined by the PMS-NADH generating system approach described by Singh and Rajini (2004) with minor modifications. One hundred $\mu \mathrm{L}$ of various concentrations $(25,50,100$, and 200 $\mu \mathrm{g} / \mathrm{mL}$ ) of each sample solution and $1 \mathrm{~mL}$ of $0.1 \mathrm{M}$ phosphate buffer (pH 7.4) were mixed. Then, $100 \mu \mathrm{L}$ of $150 \mu \mathrm{M}$ NBT, $100 \mu \mathrm{L}$ of $468 \mu \mathrm{M}$ NADH, and $20 \mu \mathrm{L}$ of $60 \mu \mathrm{M}$ PMS were added. The mixture was incubated at room temperature for $8 \mathrm{~min}$, and absorbance was measured at $560 \mathrm{~nm}$. Ascorbic acid and gallic acid were used as positive controls.

\section{Nitrite scavenging ability}

The nitrite scavenging assay was carried out according to the method of Yin et al. (2007) with minor modifications. Two hundred $\mu \mathrm{L}$ of each sample was mixed with $200 \mu \mathrm{L}$ of $1 \mathrm{mM}$ nitrite sodium. Then, $1.6 \mathrm{~mL}$ of $0.1 \mathrm{M} \mathrm{HCl}$ buffer $(\mathrm{pH}$ 1.2 adjusted with $\mathrm{NaOH}$ ) or $0.2 \mathrm{M}$ citrate buffer at $\mathrm{pH} 4.2$ or 6.0 was added. After a $1 \mathrm{~h}$ pre-incubation at $37^{\circ} \mathrm{C}, 200 \mu \mathrm{L}$ of solution was removed and mixed with $400 \mu \mathrm{L}$ of $2 \%$ acetic acid. Then, Griess reagent $[0.1 \%$ aqueous solution of naphthylethylenediamine dihydrochloride, $40 \mu \mathrm{L} ; 1 \%$ sulfanilamide (in $5 \%$ phosphoric acid), $40 \mu \mathrm{L}$ ] was added. The reactants were mixed by vigorous shaking and kept at room temperature for $15 \mathrm{~min}$. Absorbance was measured at $515 \mathrm{~nm}$. BHA was used as the positive control.

\section{Total antioxidant activity}

Total antioxidant activity was measured according to the method of Li et al. (2010) with some modifications and expressed as BHA and ascorbic acid equivalents. BHA and ascorbic acid were prepared at five concentrations of 20-100 $\mu \mathrm{g} / \mathrm{mL}$. Two hundred $\mu \mathrm{L}$ of each sample ( $1 \mathrm{mg} / \mathrm{mL}), \mathrm{BHA}$, or ascorbic acid was mixed with $200 \mu \mathrm{L}$ of $0.6 \mathrm{M}$ sulfuric acid in a $1.5 \mathrm{~mL}$ tube. Then, $200 \mu \mathrm{L}$ of $28 \mathrm{mM}$ sodium phosphate was added to the tubes and $200 \mu \mathrm{L}$ of $4 \mathrm{mM}$ ammonium molybdate solutions was added to the mixture. All tubes were shaken vigorously and incubated for $90 \mathrm{~min}$ at $95^{\circ} \mathrm{C}$. Absorbance was measured at $695 \mathrm{~nm}$ against a blank. 


\section{Cell line and cell culture}

The RAW 264.7 cell line was purchased from the Korean Cell Line Bank (Seoul, Korea). RAW 264.7 cells were maintained in RPMI 1640 supplemented with 10\% FBS, 100 $\mathrm{U} / \mathrm{mL}$ of penicillin, and $100 \mu \mathrm{g} / \mathrm{mL}$ of streptomycin. The cells were incubated at $37^{\circ} \mathrm{C}$ in a humidified atmosphere of $95 \%$ air and $5 \% \mathrm{CO}_{2}$.

\section{Cell viability assay}

The cytotoxicity of samples on RAW 264.7 cells was investigated. Cells were seeded into 96-well plates at a density of $1 \times 10^{5}$ cells/well for $16 \mathrm{~h}$ and then exposed to medium in the presence of different sample concentrations for $24 \mathrm{~h}$. After removing the supernatant from each well, $10 \mu \mathrm{L}$ of MTT solution ( $5 \mathrm{mg} / \mathrm{mL}$ in phosphate-buffered saline) and $90 \mu \mathrm{L}$ of FBS-free medium were added to each well followed by a $4 \mathrm{~h}$ incubation at $37^{\circ} \mathrm{C}$. The dark blue formazan crystals formed inside the intact mitochondria were solubilized with $100 \mu \mathrm{L}$ of MTT stop solution (containing $10 \%$ sodium dodecyl sulfate and $0.01 \mathrm{M} \mathrm{HCl}$ ). The amount of MTT formazan was quantified by measuring absorbance at $550 \mathrm{~nm}$ using an enzyme-linked immunosorbent assay (ELISA) plate reader (ELx800TM, Bio-Tek, Winooski, VT, USA). The optical density of formazan formed in the control cells was considered $100 \%$ viability. Cell viability was expressed as a percentage of the control culture value.

\section{Quantification of NO production in LPS-induced RAW}

\section{7 cells}

RAW 264.7 cells were plated in 96-well cell plate and stimulated with LPS $(2 \mu \mathrm{g} / \mathrm{mL})$ in the presence or absence of various concentration of samples for $24 \mathrm{~h}$. Aliquots of $100 \mu \mathrm{L}$ of cell culture medium were mixed with Griess reagent $[0.1 \%$ aqueous solution of naphthyl-ethylenediamine dihydrochloride, $50 \mu \mathrm{L} ; 1 \%$ sulfanilamide (in $5 \%$ phosphoric acid), $50 \mu \mathrm{L}$ ] at room temperature. The absorbance was determined at $550 \mathrm{~nm}$ using an ELISA plate reader (ELx800TM).

\section{Statistical analyses}

All tests were carried out independently in triplicate. Data are expressed as mean \pm standard derivation. One-way analysis of variance was used to determine the significant differences between the groups followed by Dunnett's $t$-test for multiple comparisons. Values of $* p<0.05$ were considered significant. All analyses were performed using SPSS for Windows XP, version 18.0 (SPSS Inc., Chicago, IL, USA).

\section{Results}

\section{Total phenolic and total flavonoid contents}

The effect of light treatment on $S$. deltoides yield was studied after extraction with aqueous methanol. As shown in Table 1, the control sample, $35 \%$ shade-treated sample, and 55\% shadetreated sample produced yields of $14.14,13.51$, and $14.52 \%$, respectively. Compared the three extracts, control showed the highest phenolic content $(292.99 \pm 2.86 \mathrm{Tan} \mathrm{mg} / \mathrm{g}$ extract $)$ and the highest flavonoid content $(22.63 \pm 1.64$ Que $\mathrm{mg} / \mathrm{g}$ extract). $55 \%$ shade showed the lowest content in both phenolic (236.41 $\pm 2.21 \mathrm{Tan} \mathrm{mg} / \mathrm{g}$ extract $)$ and flavonoid $(2.60 \pm 1.73$ Que $\mathrm{mg} / \mathrm{g}$ extract).

\section{DPPH radical scavenging activity}

The value of $\mathrm{IC}_{50}$ of no shade was the lowest in three treatment, it means that the no shade possess the strongest DPPH scavenging ability (Table 1). The DPPH scavenging ability of $35 \%$ shade was between the no shade and $55 \%$ shade. The $\mathrm{IC}_{50}$ value of $55 \%$ shade was significantly larger

Table 1. Effect of shade treatment on yield and DPPH free radical-scavenging activity of Synurus deltoides

\begin{tabular}{ccc}
\hline \hline Extracts & $\begin{array}{c}\text { Yield } \\
(\%)^{\mathrm{z}}\end{array}$ & $\begin{array}{c}\text { DPPH free radical scavenging activity } \\
\left(\mathrm{IC}_{50}\right)^{\mathrm{y}}\end{array}$ \\
\hline No shade & 14.14 & $17.65 \pm 0.87^{\mathrm{c}}$ \\
$35 \%$ shade & 13.51 & $18.42 \pm 0.38^{\mathrm{c}}$ \\
$55 \%$ shade & 14.52 & $21.49 \pm 0.49^{\mathrm{d}}$ \\
\hline Positive & & \\
control & & $3.09 \pm 0.07^{\mathrm{a}}$ \\
BHA & - & $13.34 \pm 0.04^{\mathrm{b}}$ \\
\hline
\end{tabular}

${ }^{\mathrm{z}}$ Extraction yield (\%) is expressed as: (sample extract weight / sample weight) $\times 100$.

${ }^{\mathrm{y}} \mathrm{IC}_{50}$ : The effective concentration at which DPPH radicals were scavenged by $50 \%$. L-Ascorbic acid was used as a positive control. Values are means of three determinations \pm standard deviation $(n=3)$. Different letters of upper index in the same column are significantly different by Duncan's multiple range test $(p<0.05)$. 
than that of no shade or $35 \%$ shade. Results showed that the control was better to be a DPPH radical scavenger.

\section{Total antioxidant activity}

Total antioxidant activity of the different samples was expressed as BHA and ascorbic acid equivalents (Table 2). No shade revealed the highest values $[(107.13 \pm 1.15)$ BHA

Table 2. Effect of shade treatment on total antioxidant activity of Synurus deltoides

\begin{tabular}{ccc}
\hline \hline Extracts & $\begin{array}{c}\text { BHA equivalent } \\
(\mathrm{mg} / \mathrm{g})\end{array}$ & $\begin{array}{c}\text { Ascorbic acid equivalent } \\
(\mathrm{mg} / \mathrm{g})\end{array}$ \\
\hline No shade & $107.13 \pm 1.15^{\mathrm{c}}$ & $71.80 \pm 0.80^{\mathrm{c}}$ \\
$35 \%$ shade & $102.50 \pm 0.61^{\mathrm{b}}$ & $68.58 \pm 0.43^{\mathrm{b}}$ \\
$55 \%$ shade & $90.38 \pm 0.86^{\mathrm{a}}$ & $60.16 \pm 0.60^{\mathrm{a}}$ \\
\hline
\end{tabular}

BHA and ascorbic acid were used as standards for measuring the total antioxidant activity.

Values are means of three determinations \pm standard deviation $(n=3)$. Different letters of upper index in the same column are significantly different.

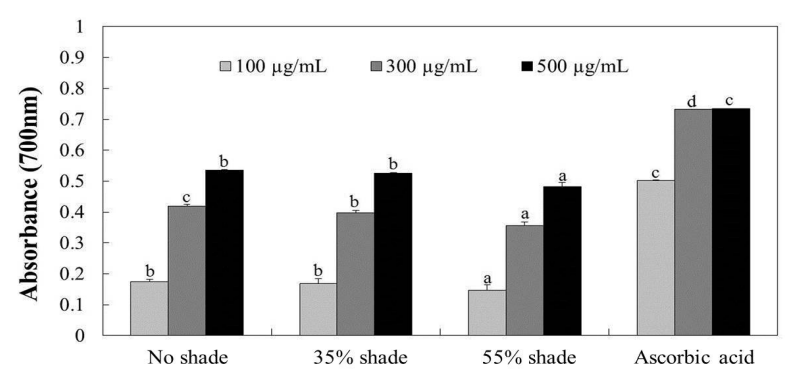

Fig. 1. Effect of shade treatment on total reducing power activity of Synurus deltoides. Each value is expressed as the mean $\pm \mathrm{SD}$ $(\mathrm{n}=3)$. Values at the same concentration are significantly different by Duncan's multiple range test $(p<0.05)$.

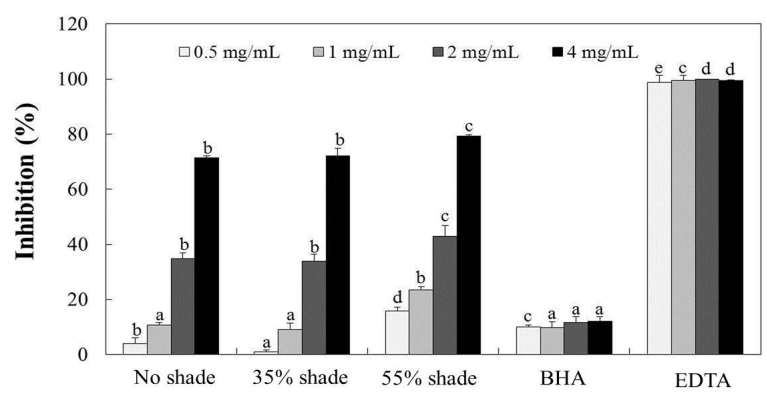

Fig. 2. Effect of shade treatment on metal chelating activity of Synurus deltoides. Each value is expressed as the mean $\pm \mathrm{SD}$ $(\mathrm{n}=3)$. Values at the same concentration are significantly different by Duncan's multiple range test $(p<0.05)$. equivalent $\mathrm{mg} / \mathrm{g}$ and $(71.80 \pm 0.80)$ ascorbic acid equivalent $\mathrm{mg} / \mathrm{g}]$, followed by $35 \%$ shade [(102.50 \pm 0.61$)$ BHA equivalent $\mathrm{mg} / \mathrm{g}$ and $(68.58 \pm 0.43)$ ascorbic acid equivalent $\mathrm{mg} / \mathrm{g}]$, and $55 \%$ shade $[(90.38 \pm 0.86)$ BHA equivalent $\mathrm{mg} / \mathrm{g}$ and $(60.16$ \pm 0.60 ) ascorbic acid equivalent $\mathrm{mg} / \mathrm{g}]$.

\section{Reducing power activity}

The results shown in Fig. 1 revealed that no shade and 35\% shade had significantly stronger reducing power compared with that of $55 \%$ shade. No shade and $35 \%$ shade exhibited the same reducing power at concentrations of 100 and $500 \mu \mathrm{g} / \mathrm{mL}$. However, at a concentration of $300 \mu \mathrm{g} / \mathrm{mL}$, no shade exhibited higher reducing power than that of $35 \%$ shade. All samples showed significantly lower reducing power compared with that of ascorbic acid.

\section{Metal chelating activity}

As shown in Fig. 2, metal chelating activity of the samples increased with increasing concentration. The chelating ability of $55 \%$ shade was significantly greater than that of no shade and $35 \%$ shade and no significant difference in scavenging capacity was observed between no shade and $35 \%$ shade at concentrations of 1,2 , or $4 \mathrm{mg} / \mathrm{mL}$. The metal chelating activity of the samples was stronger than that of BHA when concentrations were 2 or $4 \mathrm{mg} / \mathrm{mL}$. At a concentration of $4 \mathrm{mg} / \mathrm{mL}$, the percentage inhibition of samples reached its maximum, which was significantly lower compared with that of EDTA.

\section{Superoxide radical scavenging activity}

All three samples showed an obvious scavenging effect on the superoxide radical, and no significant differences were observed in the scavenging capacity at 25,50 , or $100 \mu \mathrm{g} / \mathrm{mL}$ (Fig. 3). However, at a concentration of $200 \mu \mathrm{g} / \mathrm{mL}$, the percentage inhibitory activity of the samples against the superoxide radical decreased and the decline of $35 \%$ shade and $55 \%$ shade was significantly steeper than that of no shade. When the concentration was $100 \mu \mathrm{g} / \mathrm{mL}$, the samples exhibited the strongest superoxide radical scavenging ability which was stronger than that of ascorbic acid but lower than that of gallic acid.

\section{Nitric oxide (NO) inhibition activity}

The scavenging activity of the samples against nitrite by 


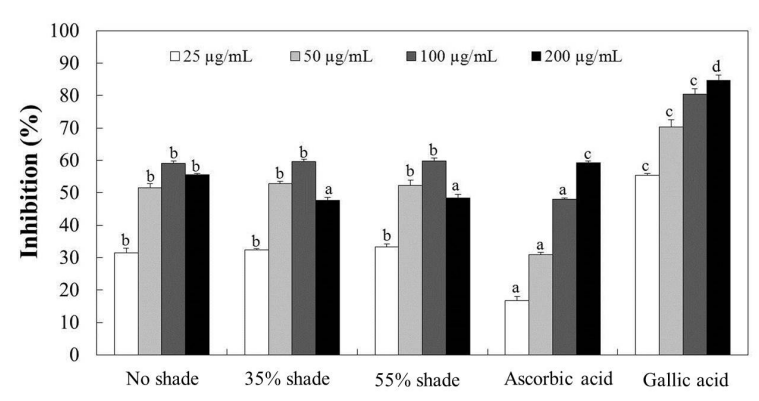

Fig. 3. Effect of shade treatment on superoxide radical scavenging activity of Synurus deltoides. Each value is expressed as the mean $\pm \mathrm{SD}(\mathrm{n}=3)$. Values at the same concentration are significantly different by Duncan's multiple range test $(\mathrm{p}<0.05)$.

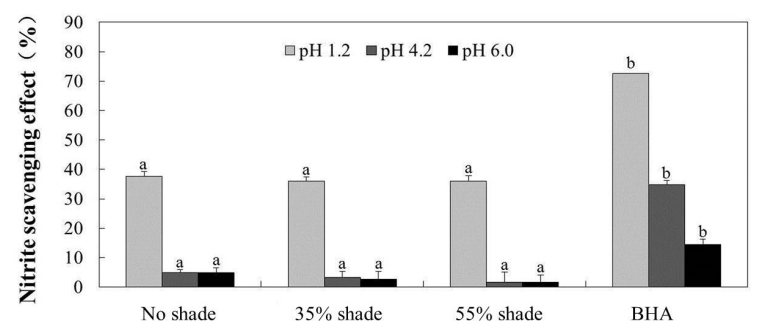

Fig. 4. Effect of shade treatment on nitrite scavenging activity of Synurus deltoides on the different acidic conditions. Each value is expressed as the mean $\pm \mathrm{SD}(\mathrm{n}=3)$. Values in the same column are significantly different by Duncan's multiple range test $(p<0.05)$.

sodium nitrite was investigated, and the results are presented in Fig. 4. The percentage inhibition of the samples and BHA at $\mathrm{pH} 1.2$ was significantly higher than that at $\mathrm{pH} 4.2$ or 6.0. In addition, the scavenging activity was not significantly different among the three samples under the same $\mathrm{pH}$ conditions. BHA exhibited stronger nitrite scavenging activity than all samples at each $\mathrm{pH}$.

\section{Quantification of NO production in LPS-induced RAW}

\section{7 cells}

We measured the cytotoxicity of $S$. deltoides extracts on RAW 264.7 cells. As shown in Fig. 5A, the cell viability rate was not reduced after treated cells with no shade, $35 \%$ shade, or $55 \%$ shade. In order to investigate the NO inhibition ability, LPS was used to stimulate RAW 264.7 cells. NO production was measured by Griess reaction through the cell response to inflammatory. Our results in Fig. 5B demonstrated that all samples had the same potency on NO inhibition at $100 \mu \mathrm{g} / \mathrm{mL}$.
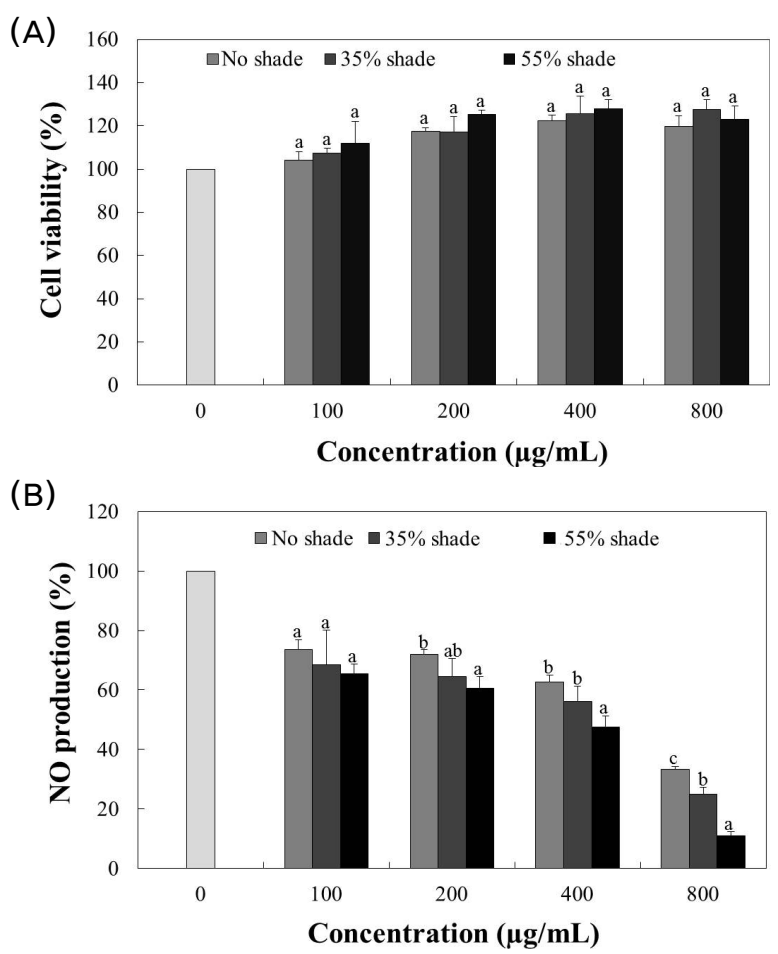

Fig. 5. Effect of shade treatment on cell viability (A) and NO production (B) of Synurus deltoides in LPS induced RAW 264.7 cells. Each value is expressed as the mean $\pm \mathrm{SD}(\mathrm{n}=3)$. Values at the same concentration are significantly different by Duncan's multiple range test $(p<0.05)$.

NO production decreased as sample concentration increased. $55 \%$ shade showed significantly higher inhibition of NO production than that of no shade or $35 \%$ shade at 400 and $800 \mu \mathrm{g} / \mathrm{mL}$.

\section{Discussion}

Phenolic compounds are secondary metabolites synthesized which contain hydroxylated derivatives of benzoic acid and cinnamic acids. Phenolics play an important role in plant as antioxidants and protective agents (Naczk and Shahidi, 2006). These compounds possess the effect not only against invading bacteria and other types of environmental stress (Ndhlala et al., 2007), but also on protect DNA from oxidative damaged, antioxidative, antimicrobial and antiinflammatory (Kim et al., 2003). Flavonoids are phytochemicals including flavanones, flavones, flavonols, isoflavonoids, anthocyanins, and flavans (Peterson and Dwyer, 1998). The beneficial effect of flavonoids have been reported as antioxidant, antifungal, anticancerous 
Table 3. Effect of shade treatment on total phenolic and flavonoid contents of Synurus deltoides

\begin{tabular}{ccc}
\hline \hline Extracts & $\begin{array}{c}\text { Phenolic content } \\
(\text { Tan } \mathrm{mg} / \mathrm{g} \text { extract })^{\mathrm{z}}\end{array}$ & $\begin{array}{c}\text { Flavonoid content } \\
(\text { Que } \mathrm{mg} / \mathrm{g} \text { extract })^{\mathrm{y}}\end{array}$ \\
\hline No shade & $292.99 \pm 2.86^{\mathrm{c}}$ & $22.63 \pm 1.64^{\mathrm{c}}$ \\
$35 \%$ shade & $269.58 \pm 2.44^{\mathrm{b}}$ & $14.37 \pm 3.83^{\mathrm{b}}$ \\
$55 \%$ shade & $236.41 \pm 2.21^{\mathrm{a}}$ & $2.60 \pm 1.73^{\mathrm{a}}$ \\
\hline
\end{tabular}

${ }^{\mathrm{z}}$ Tannic acid (Tan) was used as a standard for measuring the total phenolic content. ${ }^{\mathrm{y}}$ Quercetin (Que) was used as a standard for measuring the total flavonoid content.

Values are means of three determinations \pm standard deviation $(n=3)$. Different letters of upper index in the same column are significantly different by Duncan's multiple range test $(p<0.05)$.

and antiinflammatory activity (López-Posadas et al., 2008). Therefore, it is necessary to determine the phenolic and flavonoid compounds when measuring biological activity. The control treatment had significantly higher total phenolic and flavonoid contents than that of the other extracts (Table 3). 1,1-Diphenyl-2-picryl-hydrazyl (DPPH) is a stable free radical and in its structure there is an odd electron (Jin and Chen, 1998). In order to evaluate antioxidant effective, DPPH radical scavenging capacity assay has always been used of natural extracts, but this assay is sensitive to light, oxygen, and impurities (Mot et al., 2011). Result of this assay may be interfered by light, oxygen, and impurities, which may lead to increase the experimental error. Therefore, the reaction process of DPPH assay was kept in dark and the level of DPPH scavenging was determined quickly by absorbance at $517 \mathrm{~nm}$. No shade and 35\% shade possessed higher DPPH free radical scavenging activity than that of $55 \%$ shade (Table 1). Total antioxidant activity was measured according to the molybdenum blue assay. The formation of isopoly-molybdenum blue results in an intense blue color and has been used as a sensitive test for reducing reagents. High absorbance values indicate that a sample possesses higher antioxidant activity (Puoci et al., 2011). No shade exhibited significantly higher total antioxidant activity that may have been attributed to its chemical composition and high phenolic and flavonoid contents. The reducing power assay has been became a useful test with inexpensive reagents and equipment. The reaction process of this assay was with an appropriate speedy through a wide concentration range (Berker et al., 2007). In food and science, ferrous reducing power assay has been widely used to estimate the antioxidant activity (Kuda and Yano, 2009). Although the reducing power of no shade and $35 \%$ shade was significantly different at $300 \mu \mathrm{g} / \mathrm{mL}$ (Fig. 1), the numerical values were approximate and they were not significantly different at 100 or $500 \mu \mathrm{g} / \mathrm{mL}$. Therefore, the significant difference may have been caused by a deviation. Iron biological characters include enzyme co-factor, oxygen transport and redox reactions (Kontoghiorghes, 1995). Iron chelation plays an important role in the regulation of transfusion-dependent anaemias. For iron-overloaded patients, iron-chelating therapy is always been used (Cappellini, 2005). Therefore, the metal chelating activity of the three samples was measured, and the $55 \%$ shade sample revealed the strongest chelating ability among the samples at any concentration (Fig. 2). Superoxide anion (O2-) production is stimulated in neutrophils and treats with activators of protein kinase (Kitaoka et al., 2005). Superoxide scavenging activities were measured by the PMS-NADH system (Samak et al., 2009). Therefore, it is necessary to identify some antioxidants with strong superoxide radical scavenging ability. There was a fact that nitrate ingestion may cause death of gastric cancer (Kako et al., 1992). Nitric oxide (NO), peroxynitrite (ONOO_) and nitrogen dioxide $(\mathrm{NO} 2)$ as reactive nitrogen intermediates are one of the important reason introduce inflammatory process (Yen et al., 2001). In this study, the NO inhibition ability of the samples at $\mathrm{pH} 1.2$ was higher than that at $\mathrm{pH} 4.2$ or 6.0 , which indicated that $\mathrm{pH}$ 1.2 was more advantageous for samples to scavenge nitrite.

Inflammation is generally recognized to be a cause of numerous diseases such as cancer, diabetes, atherosclerosis, sepsis, and obesity (O'Neill et al., 2009). Inflammatory processes are mediated by multiple molecular mechanisms. During the inflammatory process, a number of different inflammatory mediators, including $\mathrm{NO}$, prostaglandin E2, and tumor necrosis factor- $a$ generated by macrophages upon stimulation with LPS (a primary component of the Gramnegative bacteria cell wall) are representative toxins and play an important role in immune-pathology of acute or chronic inflammatory diseases (Castro et al., 2006). In this study, none of the samples showed a significant effect on inhibiting $\mathrm{NO}$ at $100 \mu \mathrm{g} / \mathrm{mL}$. However, a significant difference was observed at a higher concentration of $800 \mathrm{\mu g} / \mathrm{mL}$. The $55 \%$ shade sample 
displayed significantly greater NO inhibitory capacity than that of the $35 \%$ shade sample, which showed significantly greater NO inhibition capacity than the no shade sample at $800 \mu \mathrm{g} / \mathrm{mL}$. These results suggest that the effect of light treatment on the anti-inflammatory activity of $S$. deltoids was remarkable and that reducing the light intensity during their growth was more beneficial to exert anti-inflammatory effects.

In conclusion, we demonstrated the antioxidant and antiinflammatory activities of $S$. deltoids, which were treated with different light intensities during growth. Samples with different light treatments exhibited different biological activities. The effects of the light condition on total antioxidant activity and the accumulation of phenolic and flavonoid contents in $S$. deltoids were clear. The total phenolic and flavonoid contents of the $55 \%$ shade sample were significantly lower than that of the $35 \%$ shade sample whose phenolic and flavonoid contents were lower than that of the no shade sample. In the total antioxidant activity assay, samples showed similar results for total phenolic and flavonoid contents. Only the 55\% shade sample exhibited a significant difference in total reducing power activity and metal chelating activity with the no shade sample at all concentrations. The superoxide radical scavenging activities of the $35 \%$ and $55 \%$ shade samples were significantly different from the no shade sample only at a concentration of $200 \mu \mathrm{g} / \mathrm{mL}$. In addition, no significant difference in nitrite scavenging activity or cytotoxicity was observed among the three samples. The 55\% shade sample exhibited greater antiinflammatory activity.

\section{Acknowledgement}

This study was supported by the Cooperative Research Program for Agriculture Science and Technology Development (Project No. C1009413-01-01) of the Rural Development Administration, Republic of Korea.

\section{Literature Cited}

Berker, K.I., K. Güçlü, İ. Tor and R. Apak. 2007. Comparative evaluation of $\mathrm{Fe}(\mathrm{III})$ reducing power-based antioxidant capacity assays in the presence of phenanthroline, bathophenanthroline, tripyridyltriazine (FRAP), and ferricyanide reagents. Talanta 72:1157-1165.

Cappellini, M.D. 2005. Iron-chelating therapy with the new oral agent ICL670 (Exjadew). Best Pract. Res. Clin. Haematol. 18:289-298.

Castro, S.M., A. Guerrero-Plata, G. Suarez-Real, P.A. Adegboyega, G.N. Colasurdo, A.M. Khan, R.P. Garofalo and A. Casola. 2006. Antioxidant treatment ameliorates respiratory syncytial virus-induced disease and lung inflammation. Am. J. Respir. Crit. Care Med. 15:136-139.

Cook, N.C. and S. Samman. 1996. Flavonoids-Chemistry, metabolism, cardioprotective effects, and dietary sources. J. Nutr. Biochem. 7:66-76.

Guidi, L., E. Degl'Innocenti, D. Remorini, S. Biricolti, A. Fini, F. Ferrini, F.P. Nicese and M. Tattini. 2011. The impact of UV-radiation on the physiology and biochemistry of Ligustrum vulgare exposed to different visible-light irradiance. Environ. Exp. Bot. 70:88-95.

Hu, W., S. Heo and M.H. Wang. 2009a. Antioxidant and antiinflammatory activity of Kalopanax pictus leaf. J. Korean Soc. Appl. Biol. Chem. 52:360-366.

Hu, W., W. Shen and M.H. Wang. 2009b. Free radical scavenging activity and protective ability of methanolic extract from Duchesnea indica against protein oxidation and DNA damage. J. Food Sci. Nutr. 14:277-282.

Jeong, C.H., J.H. Kwak, J.H. Kim, G.N. Choi, D.O. Kim and H.J. Heo. 2011. Neuronal cell protective and antioxidant effects of phenolics obtained from Zanthoxylum piperitum leaf using in vitro model system. Food Chem. 125:417-422.

Jin, Z.Q. and X. Chen. 1998. A Simple Reproducible Model of Free Radical-Injured Isolated Heart Induced by 1,1-Diphenyl2-Picryl-Hydrazyl (DPPH). J. Pharmacol. Toxicol. Methods 39:63-70.

Jung, M.J., S. Heo and M.H. Wang. 2008a. Antioxidant activities of different parts of Synurus deltoids Nakai extracts in vitro. Food Sci. Biotechnol. 17:1156-1159.

Jung, M.J., S. Heo and M.H. Wang. 2008b. Free radical scavenging and total phenolic contents from methanolic extracts of Ulmus davidiana. Food Chem. 108:482-487.

Kako, Y., Y. Toyoda, Y. Hatanaka, Y. Suwa, H. Nukaya and M. Nagao. 1992. Inhibition of in vitro lipid peroxidation by stable steroidic nitroxyl radicals. Mutat. Res. 282:19-125.

Kim, D.O., S.W. Jeong and C.Y. Lee. 2003. Antioxidant capacity of phenolic phytochemicals from various cultivars of plums. Food Chem. 81:3221-326.

Kitaoka, N., G. Liu, N. Masuoka, K. Yamashita, M. Manabe and 
H. Kodama. 2005. Effect of sulfur amino acids on stimulusinduced superoxide generation and translocation of $\mathrm{p} 47 \mathrm{phox}$ and p67phox to cell membrane in human neutrophils and the scavenging of free radical. Clin. Chim. Acta. 353:109-116.

Kontoghiorghes, G.J. 1995. Comparative efficacy and toxicity of desferrioxamine, deferiprone and other iron and aluminium chelating drugs. Toxicol. Lett. 80:1-18.

Kuda, T. and T. Yano. 2009. Changes of radical-scavenging capacity and ferrous reducing power in chub mackerel Scomber japonicus and Pacific saury Cololabis saira during 4-C storage and retorting. LWT-Food Sci. Technol. 42:1070-1075.

Li, C., H.J. Son, C. Huang, S.K. Lee, J. Lohakare and M.H. Wang. 2010. Comparison of Crataegus pinnatifida Bunge var. typica Schneider and C. pinnatifida Bunge fruits for antioxidant, anti-a-glucosidase, and anti-inflammatory activities. Food Sci. Biotechnol. 19:769-775.

Liu, H., L. Wang and M.H. Wang. 2011. Antioxidant and nitric oxide release inhibition activities of methanolic extract from Clerodendrum cyrtophyllum Turcz. Hortic. Environ Biotechnol. 52:1-6.

López-Posadas, R., I. Ballester, A.C. Abadía-Molina, R. Suárez, A. Zarzuelo, O. Martínez-Augustin and F.S. Medina. 2008. Effect of flavonoids on rat splenocytes, a structure-activity relationship study. Biochem. Pharmacol. 76:495-506.

Luthria, D.L. 2008. Influence of experimental conditions on the extraction of phenolic compounds from parsley (Petroselinum crispum) flakes using a pressurized liquid extractor. Food Chem. 107:745-752.

Moț, A.C., R. Silaghi-Dumitrescu and C. Sârbu. 2011. Rapid and effective evaluation of the antioxidant capacity of propolis extracts using DPPH bleaching kinetic profiles; FT-IR and UV-vis spectroscopic data. J. Food Compost. Anal. 24:516- 522.

Naczk, M. and F. Shahidi. 2006. Phenolics in cereals, fruits and vegetables: Occurrence, extraction and analysis. J. Pharm. Biomed. Anal. 41:1523-1543.

Ndhlala, A.R., A. Kasiyamhuru, C. Mupure, K. Chitindingu, M.A. Benhura and M. Muchuweti. 2007. Phenolic composition of Flacourtia indica, Opuntia megacantha and Sclerocarya birrea. Food Chem. 103:82-87.

O’Neill, L.A., C.E. Bryant and S.L. Doyle. 2009. Therapeutic targeting of Toll-like receptors for infectious and inflammatory diseases and cancer. Pharmacol. Rev. 61:177-197.

Park, J.H., K.H. Son, S.W. Kim, H.W. Chang, K.H. Bae, S.S.
Kang and H.P. Kim. 2004. Antiinflammatory activity of Synurus deltoids. Phytother Res. 18:930-933.

Peterson, J. and J. Dwyer. 1998. Favonoids: dietary occurrence and biochemical activity. Nutr Res. 18:1995-2018.

Puoci, F., F. Iemma, U.G. Spizzirri, D. Restuccia, V. Pezzi, R. Sirianni, L. Manganaro, M. Curcio, O. Parisi, G. Parisi and N. Nevio Picci. 2011. Antioxidant activity of a Mediterranean food product: "fig syrup". Nutrients 3:317-329.

Samak, G., R.P. Shenoy, S.M. Manjunatha and K.S. Vinayak. 2009. Superoxide and hydroxyl radical scavenging actions of botanical extracts of Wagatea spicata. Food Chem. 115:631634.

Singh, N. and P.S. Rajini. 2004. Free radical scavenging activity of an aqueous extract of potato peel. Food Chem. 85:611-616.

Song, Y.G., B. Liu, L.F. Wan, M.H. Li and Y. Liu. 2006. Damage to the oxygen-evolving complex by superoxide anion, hydrogen peroxide, and hydroxyl radical in photoinhibition of photosystem II. Photosyn. Res. 90:67-78.

Tyug, T.S., K.N. Prasad and A. Ismail. 2010. Antioxidant capacity, phenolics and isoflavones in soybean by-products. Food Chem. 123:583-589.

Yen, G.C., H.H. Lai and H.Y. Chou. 2001. Nitric oxidescavenging and antioxidant effects of Uraria crinita root. Food Chem. 74:471-478.

Yin, J., G.J. Kwon and M.H. Wang. 2007. The antioxidant and cytotoxic activities of Sonchus oleraceus L. extracts. Nutr. Res. Pract. 1:189-194.

Sathuvan, M., A. Vignesh, R. Thangam, P. Palani, R. Rengasamy and K. Murugesan. 2012. In vitro antioxidant and anticancer potential of bark of Costus pictus D.DON. Asian Pac. J. Trop. Biomed. 2:S741-S749.

Aremu, AO., S.O. Amoo, A.R. Ndhlala, J.F. Finnie and J.V. Staden. 2011. Antioxidant activity, acetylcholinesterase inhibition, iridoid content and mutagenic evaluation of Leucosideasericea. Food Chem. Toxicol. 49:1122-1128.

Milos, M. and D. Makota. 2012. Investigation of antioxidant synergisms and antagonisms among thymol, carvacrol, thymoquinone and p-cymene in a model system using the Briggs-Rauscher oscillating reaction. Food Chem. 131:296-299.

Lue, B.M., N.S. Nielsen, C. Jacobsen, L. Hellgren, Z. Guo and X. Xu. 2010. Antioxidant properties of modified rutin esters by DPPH, reducing power, iron chelation and human low density lipoprotein assays. Food Chem. 123:221-230. 